\title{
SECULAR CHANGES IN THE INCIDENCE OF MALFORMATIONS OF THE CENTRAL NERVOUS SYSTEM
}

\author{
BY
}

\author{
BRIAN MACMAHON*, R. G. RECORD, and THOMAS McKEOWN \\ From the Department of Social Medicine, University of Birmingham
}

In a previous communication (Record and McKeown, 1949) it was noted that in Birmingham the incidence of anencephalus and spina bifida decreased during the years 1940-47, while the incidence of hydrocephalus remained fairly constant. It was tentatively suggested that this decrease might be correlated with changes in the parity distribution of births, since it was shown that the incidence of anencephalus and spina bifida is associated with birth order. We propose here to examine this suggestion more critically, making use of statistics for additional years and of more detailed information than was previously available about the parity distribution of the general population of births.

Table I (see Fig. 1) gives the incidence of malformations of the central nervous system notified as stillbirths or infant deaths in Birmingham for the period 1936-49. Anencephalus associated with spina bifida is classified under anencephalus, and spina bifida with hydrocephalus under spina bifida. During the years 1940-49 the incidence of anencephalus and spina bifida fell sharply; the incidence of hydrocephalus showed no consistent variation. The significance of these changes

* In receipt of a personal grant from the Medical Research Council.

TABLE I

InCidence (PER thousand total births) of Malformations of the Central Nervous System Birmingham, 1936-49

\begin{tabular}{|c|c|c|c|}
\hline \multirow{2}{*}{ Years } & \multicolumn{3}{|c|}{ Malformations } \\
\hline & Anencephalus & Spina bifida & Hydrocephalus \\
\hline $\begin{array}{l}1936 \text { and } 1937 \\
1938 \text { and } 1939 \\
1940 \text { and } 1941 \\
1942 \text { and } 1943 \\
1944 \text { and } 1945 \\
1946 \text { and } 1947 \\
1948 \text { and } 1949\end{array}$ & $\begin{array}{ll}2 \cdot 0 & (69) \\
2 \cdot 5 & (90) \\
2 \cdot 8 & (87) \\
2 \cdot 7 & (101) \\
2 \cdot 2 & (93) \\
1 \cdot 8 & (85) \\
1 \cdot 6 & (65)\end{array}$ & $\begin{array}{ll}2 \cdot 6 & (91) \\
2 \cdot 4 & (88) \\
3 \cdot 0 & (93) \\
2 \cdot 9 & (112) \\
2 \cdot 2 & (92) \\
1 \cdot 9 & (92) \\
1 \cdot 7 & (71)\end{array}$ & $\begin{array}{ll}0.9 & (31) \\
1 \cdot 4 & (51) \\
1 \cdot 1 & (33) \\
0.9 & (35) \\
0 \cdot 7 & (31) \\
1 \cdot 1 & (51) \\
0.7 & (30)\end{array}$ \\
\hline Total & $2 \cdot 18(590)$ & $2 \cdot 37(639)$ & $0.97(262)$ \\
\hline $1940-1944(a)$ & $2 \cdot 58(236)$ & $2 \cdot 84$ (259) & $0.93 \quad(85)$ \\
\hline $1945-1949(b)$ & $1 \cdot 80(195)$ & $1 \cdot 86(201)$ & $0.88 \quad(95)$ \\
\hline Difference $(a)-(b)$ & $0 \cdot 78 \pm 0 \cdot 21$ & $0 \cdot 98 \pm 0 \cdot 22$ & $0.05 \pm 0.14$ \\
\hline
\end{tabular}

Numbers in brackets are the numbers of malformations (stillbirths and infant deaths). 
MALFORMATIONS OF THE CENTRAL NERVOUS SYSTEM 255

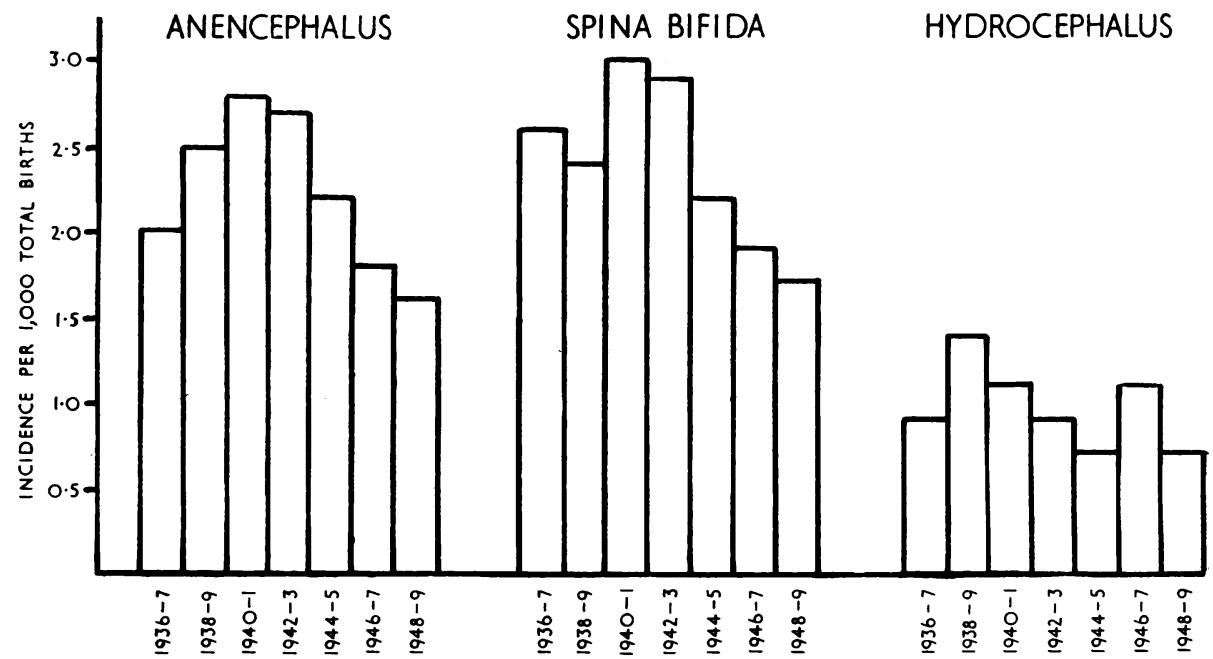

Fig. 1.-Incidence of malformations of the central nervous system. Birmingham, 1936-49.

is indicated by a comparison of the rates attributed to each malformation in the periods 1940-44 and 1945-49.

Before enquiring whether this variation is correlated with changes in the parity structure of the related population of births, we may reconsider and extend slightly the evidence of association of incidence with birth order. This association, previously demonstrated for anencephalus and spina bifida (but not for hydrocephalus) on Birmingham data, is also exhibited

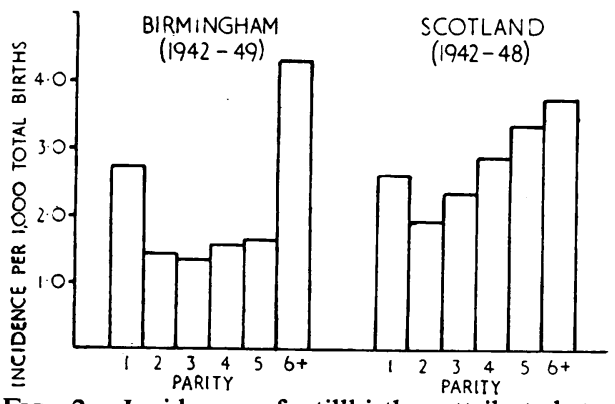

FIG. 2.-Incidence of stillbirths attributed to anencephalus related to birth rank.

for anencephalus* on Scottish data in Table II (see Fig. 2). There is good

* Since nearly all anencephalics are stillborn, the relationship between incidence and birth rank can be examined on Scottish statistics for stillbirths.

TABLE II

INCIDENCE OF ANENCEPHAlus RELATED TO BiRTH RANK

\begin{tabular}{c|c|c}
\hline \multirow{3}{*}{ Birth Rank } & \multicolumn{2}{|c}{ Incidence per 1,000 Total Births } \\
\cline { 2 - 3 } & $\begin{array}{c}\text { Birmingham 1942-1949 } \\
\text { (stillbirths and infant deaths) }\end{array}$ & $\begin{array}{c}\text { Scotland 1942-1948 } \\
\text { (stillbirths only) }\end{array}$ \\
\hline 1 & $2 \cdot 75$ & $2 \cdot 64$ \\
2 & $1 \cdot 42$ & $1 \cdot 95$ \\
3 & $1 \cdot 31$ & $2 \cdot 36$ \\
4 & $1 \cdot 53$ & $2 \cdot 88$ \\
5 & $1 \cdot 64$ & $3 \cdot 37$ \\
6 and over & $4 \cdot 32$ & $3 \cdot 73$ \\
\hline
\end{tabular}

* Of the total, 95 per cent. are stillbirths. 
agreement in the figures for Birmingham and Scotland in birth rank 1 and in birth rank 6 and over; but in Scotland incidence rises more sharply after birth rank 2, and is actually higher in birth ranks 4 and 5 than in 1 . These observations confirm the association of incidence with parity, but suggest that the risk of anencephalus is not invariably greater in the first than in the later birth ranks. This modifies somewhat the generality of the conclusion (suggested by Birmingham data) as to the importance of the proportion of first born in determining the incidence of anencephalus in a population of births.

To decide whether the change in annual incidence of the malformations is associated with changes in the parity composition of the general population of births, we require, of course, the birth rank of malformed individuals and of the related population of births. This evidence is available in Birmingham for the years 1942-49, and Table III gives the incidence of anencephalus and spina bifida in infants in birth ranks 1 to $5^{*}$ standardized for parity. The sharp fall in the rates is exhibited after standardization, and the change is if anything more regular than that shown in Table I. It is evident that the decrease in incidence is not explained by changes in the parity composition of the general population of births.

TABLE III

InCidence of ANencephalus and Spina Bifida (STIllbiRThs and INfant Deaths) in INFANTS of Birth Ranks 1-5 Standardized for Changing Parity Distribution OF BIRTHS Birmingham 1942-49

\begin{tabular}{c|cc}
\hline \multirow{2}{*}{ Year } & Estimated $\ddagger$ Incidence per 1,000 Total Births \\
\cline { 2 - 3 } & Anencephalus & Spina Bifida \\
\hline 1942 and 1943 & $2 \cdot 3$ & $2 \cdot 5$ \\
1944 and 1945 & $2 \cdot 1$ & $2 \cdot 1$ \\
1946 and 1947 & $1 \cdot 6$ & $1 \cdot 8$ \\
1948 and 1949 & $1 \cdot 4$ & $1 \cdot 7$ \\
\hline
\end{tabular}

$\$$ The birth rank distribution of the related population of total births is estimated from a random sample of 897 births, for 869 (97 per cent.) of which birth rank was recorded.

The rates examined in Tables I and III were prepared by combining Birmingham stillbirths and infant deaths attributed to the malformations. Unfortunately national rates cannot be given in the same form, and the only useful data available from national sources for consideration of secular changes in incidence of central nervous malformations are:

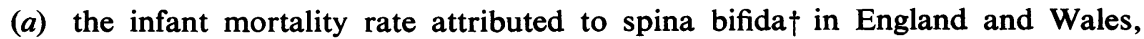

(b) the stillbirth rate attributed to anencephalus and spina bifida in Scotland.

(a) Fig. 3 illustrates the annual infant mortality attributed to spina bifida in England and Wales for the years 1931-49. The rate was fairly constant from 1932 until 1941; it increased in 1942, fell in each subsequent year until 1948, and rose slightly in 1949. The significance of the change is demonstrated in Table IV,

* Births above birth rank 5 were excluded because of small numbers.

$\dagger$ In Birmingham approximately 70 per cent. of combined stillbirths and infant deaths attributed to spina bifida were infant deaths. 


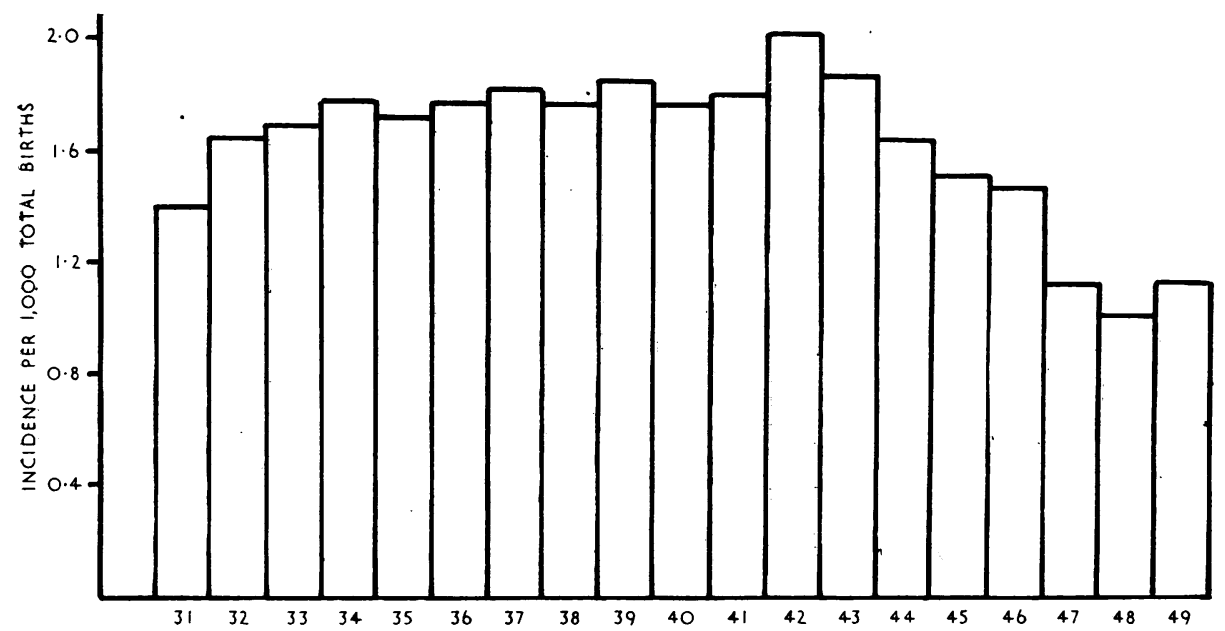

FIGURE 3.-Annual infant mortality rate attributed to spina bifida. England and Wales, 1931-49.

TABLE IV

INFANT MORTALITY RATE (PER THOUSAND LIVE BIRTHS) ATtRIBUTED to SPINA BifidA

\begin{tabular}{c|c|c}
\hline Years & England and Wales & Birmingham \\
\hline $1940-1944$ & 1.82 & 2.03 \\
$1945-1949$ & 1.26 & 1.34 \\
\hline Difference & 0.56 & 0.69 \\
& \pm 0.03 & \pm 0.19 \\
\hline
\end{tabular}

which compares the rates for the two periods 1940-44 and 1945-49. The table also makes the comparison on Birmingham infant deaths which show a similar decrease.

(b) Table V compares stillbirth rates attributed to anencephalus and spina bifida in Scotland and Birmingham in the years 1940-44 and 1945-48. In Birmingham, stillborn anencephalics show the decrease already noted in Table I (for stillbirths and infant deaths), but in Scotland there is no significant difference in the rates for the two periods. We are on less firm ground in using the spina bifida

TABLE V

STILLBIRTH RATEs (PER thousand total BIRTHS) ATtRIBUted to ANENCEPHAL US AND SPINA BifidA

\begin{tabular}{|c|c|c|c|c|}
\hline \multirow{2}{*}{ Years } & \multicolumn{2}{|c|}{ Anencephalus } & \multicolumn{2}{|c|}{ Spina Bifida } \\
\hline & Scotland & Birmingham & Scotland & Birmingham \\
\hline $\begin{array}{l}1940-1944 \\
1945-1948\end{array}$ & $\begin{array}{l}2 \cdot 57 \\
2 \cdot 40\end{array}$ & $\begin{array}{l}2.49 \\
1.65\end{array}$ & $\begin{array}{l}0.47 \\
0.39\end{array}$ & $\begin{array}{l}0 \cdot 87 \\
0.58\end{array}$ \\
\hline Difference & $\begin{array}{r}0 \cdot 17 \\
\pm 0.11\end{array}$ & $\begin{array}{r}0.84 \\
\pm 0 \cdot 22\end{array}$ & $\begin{array}{c}0.08 \\
\pm 0.044\end{array}$ & $\begin{array}{r}0.29 \\
\pm 0.13\end{array}$ \\
\hline
\end{tabular}


stillbirth rate as an index of the incidence of spina bifida because of the higher ratio of infant deaths to stillbirths in the case of this malformation. Nevertheless, it seems worth recording that the incidence of stillbirths attributed to spina bifida in Birmingham has decreased since 1940, whereas in Scotland the difference in the rates for the two periods examined is small and of doubtful significance.

\section{SUMMARY}

In recent years there has been a considerable reduction in the incidence of some of the more important malformations of the central nervous system as follows:

(i) of anencephalus in Birmingham (but not in Scotland),

(ii) of spina bifida in Birmingham, England and Wales, and possibly Scotland (although the Scottish data available are inconclusive).

We have no explanation for these secular variations, but are satisfied that they are not associated to any considerable extent with fluctuations in the parity composition of the general population of births. It will be of interest to review these observations in later years, and to extend them to other areas.

\section{REFERENCE}

Record, R. G., and McKeown, T. (1949). British Journal of Social Medicine, 4, 183. 